American Journal of Applied Sciences 5 (4): 355-368, 2008

ISSN 1546-9239

(C) 2008 Science Publications

\title{
Numerical Investigation Into The Behavior of Circular Pad Shallow Foundations Supported By Geogrid Reinforced Sand
}

\author{
${ }^{1}$ S.M. Marandi, ${ }^{1}$ M. H. Bagheripour, ${ }^{1}$ R. Rahgozar and ${ }^{2}$ A.R. Ghirian \\ ${ }^{1}$ Department of Civil Engineering, Bahonar University, Kerman, Iran \\ ${ }^{2}$ Civil Engineer Senior Expert, Tehran, Iran
}

\begin{abstract}
This study seeks to widen the pool of knowledge on the use and characteristics of geosynthetics, specifically in the area of circular foundations supported by geosynthetic reinforced sand. The main objective of the work was to increase the awareness of circular foundation systems and thus increase the accuracy of current laboratory methods. Also, compare the results with that of previous papers on the subject and to provide new model curves to estimate the bearing capacity of circular foundations. In this respect, the foundation and the soil underneath was modeled using four nots isoparameters finite element aid, while, for geogrid reinforcement, the four nots one-dimentional finite element model was used. The sand behavior was based on demolition elasto-plastic druckerprager criteria and for the reinforcement the linear criteria was used. The paper investigates the effects of the reinforcement placing properties, soil properties, reinforcement properties, and the geometric properties of circular foundations. The results showed that; the bearing capacity ratio at a settlement level for geogrid reinforced sand is effected considerably by parameters such as: reinforcement placement, reinforcement layers, reinforcement strength, geometric properties of circular foundations, and effects of using granular soils. Based on the results achieved, a number of design curves have been developed to assist with the estimation (design) of field bearing capacity of shallow foundations supported by geogrid reinforced soil. Keeping in mind the settlement limitations in real space, the curves have been developed for normal settlement levels up to a settlement ratio of $2.5 \%$.
\end{abstract}

Keywords: Circular foundation; geosynthetics; bearing capacity, settlement level.

\section{INTRODUCTION}

The use of geosynthetics in civil engineering has flourished in recent years due to its ability to improve soil properties in some manner. Specific to this study, the use of geogrid to improve the bearing capacity and settlement performance of shallow pad foundations has proven to be a cost effective foundation system. In this application geogrid has allowed the use of shallow foundations where traditionally more expensive deep foundations such as piles have been used.

Soil reinforcement including geosyntetics, galvanised steel mesh and anchoreed steel cable are used to improve the bearing capacity, and decrease the settlement in soil structures such as embankments, retaining walls, bridge abutments and foundations. The settlement and bearing capacity characteristics of foundations are dependent on many varied and interconnected parameters and conditions and predicting these relationships has been the subject of many studies.
The circular foundation, which is predominantly used in axi-symetric structures and has economic advantages over boxed foundationsm has received little research attention.

Over the last two decades, considerable advances have been made into the understanding of the behavior of reinforced soil foundations and on the applications and limitations of using geosynthetics to improve the performance of shallow foundations. Detailed investigations have been performed using small scale laboratory test models and a (limited) number of in-situ tests $[1,2,3,4,5,6,7,8]$

These studies (among others) have demonstrated that; a geosynthetic reinforcement placed below a foundation can increase both, the ultimate bearing capacity, and allowable bearing stress at a given settlement. However, due to the numerous parameters effecting the bearing capacity of shallow foundations and, limited literary records that predict the global effects of the physical and strength specifications of reinforced sand embankments, strength parameters of 
geogrid reinforcement, consider found action conditions and lack of research into geogrid reinforced circular foundations, more research is required to understand this emerging technology.

The main objective of the work was to undertake numerical investigation into the strength and settlement characteristics of circular pad foundations strengthened by using underlying geogrid reinforced granular soil. The paper investigated the various areas such as: the effect of reinforcement placement and determination of optimum placement depth and number of reinforcement layers; the effects of reinforcement strength and identification of the optimal strength; the effects of using granular soils and their benefits to shallow foundations; and the geometric properties and advantages of circular foundations.

The results are presented and analysed with the aim of increasing the awareness of circular foundation systems and thus increase the accuracy of current laboratory methods. Also, new model curves are developed to estimate the bearing capacity of circular foundations.

The Theoretical Model: The controlling, and interrelated, parameters in foundation design are bearing capacity and settlement. Hence; it is important to evaluate the bearing capacity of circular foundations at various settlements in comparison to the settlement achieved at ultimate load.

To evaluate the increase in bearing capacity, the ratio of bearing capacity of reinforced soil to that of the unreinforced soil, the bearing capacity ratio $(B C R)$ is usually used. For numerical simulation, the bearing capacity is introduced as a non-dimensional ultimate bearing capacity ratio, $B C R_{u}$, as follows:

$$
B C R_{u}=\frac{q_{u(R)}}{q_{u}}
$$

Where, $\mathrm{q}_{\mathrm{u}(\mathrm{R})}$ and $\mathrm{q}_{\mathrm{u}}=$ the ultimate bearing capacity with, and without geogrid, reinforcement respectively.

At present, most shallow foundations are designed for a limited settlement in real scale. To model this scenario BCRs will be determined at various settlement levels (e.g. $s / B=2.5 \%, 5 \%$ and $7.5 \%$ ). The $B C R$ at a settlement level of $S \leq S_{u}$ can be introduced as:

$$
B C R_{S}=\frac{q_{(R)}}{q}
$$

Where, $B C R_{S}=$ ultimate bearing capacity ratio at a settlement level of $S$, and $q_{(R)}$ and $q=$ ultimate bearing capacity with, and without, reinforcement respectively at a settlement level of $S$.
The physical model for this investigation consists of a reinforced soil-foundation system with failure boundary radiating downward and outward from the foundation contact surface which shows disipation of the stresses with depth. The parameters used in the model are: $B=$ Circular foundation diameter, $N=$ Number of geogrid layers, $b=$ Geogrid width, and $D_{f}=$ The foundation embedment depth.

The reinforced depth is $d$ and can be calculated as: $d=u+(N-\mathbf{1}) h$

The increase in foundation bearing capacity can arise from two factors: stiffness increase due to the reinforcement, and friction strength.

The value of bearing capacity ratio $\left(B C R_{u}\right.$ and $B C R_{S}$ ) for a given foundation supported by geogrid reinforcement sand depends on non-dimensional parameters such as: the top layer of geogrid depth ratio $(u / B)$, geogrid reinforcement thickness ratio $(h / B)$, the reinforcement depth ratio $(d / B)$, geogrid width ratio $(b / B)$, and number of geogrid layers $(N)$.

Based on analatical results, the optimum, and critical, ratios for the effective parameters on bearing capacity can be used. These are defined as: (1) the optimum depth ratio, $(u / B)_{\text {opt }}$ as the point at which further increases in $u / B$ occur the $B C R$ decreases (assuming other parameters remain constant), or the maximum $B C R,(2)$ the critical depth ratio $(u / B)_{\mathrm{cr}}$ as the point at which, if further increases in $u / B$ occur. Surface failure appears beneath the foundation in the soil layer above geogrid, and practically, reinforcement does not have any effect on foundation bearing capacity, and (3) for other effective bearing capacity parameters, there are optimal values, i.e. the ratios of $(h / B)_{\mathrm{opt}},(b / B)_{\mathrm{opt}},(d / B)_{\mathrm{opt}}$, and $(N)_{\mathrm{opt}}$ and these can be determined.

In finite element grids for geogrid reinforced soil, the reinforced element is shown as a horozontal line. The dimensions and boundary conditions of the geometric model are selected far enough from the foundation so as to diminish their effects on the analysis. Due to axisymetry of the model, only half of the model is used as any effects in this area are simply reflected into the other half of the model.

Foundation and soil are modeled with four nots isoparametric finite element aid and for geogrid reinforcement, four nots one dimentional finite element model is used.

The side boundaries of the model are denoted in the " $x$ " direction and beneath the model in both directions of $x$ and $y$ are assumed fixed. The soil non- 
Am. J. Applied Sci., 5 (4): 355-368, 2008

Table 1: Model technical material properties

\begin{tabular}{cccccccccc}
\hline Material & Criteria & $\begin{array}{c}\phi \\
(\text { deg. })\end{array}$ & $\begin{array}{c}C \\
\left(\mathrm{kN} / \mathrm{m}^{2}\right)\end{array}$ & $\begin{array}{c}\Psi \\
(\text { deg. })\end{array}$ & $\begin{array}{c}\gamma \\
\left(\mathrm{kN} / \mathrm{m}^{3}\right)\end{array}$ & $\begin{array}{c}E \\
\left(\mathrm{kN} / \mathrm{m}^{2}\right)\end{array}$ & $\begin{array}{c}K_{R} \\
(\mathrm{kN} / \mathrm{m})\end{array}$ & $\begin{array}{c}T_{R} \\
(\mathrm{kN} / \mathrm{m})\end{array}$ \\
\hline Foundation & Elastic & - & - & - & 24.0 & $2 \times 10^{7}$ & 0.3 & - & - \\
Sand & $\begin{array}{c}\text { Drucker- } \\
\text { Prager }\end{array}$ & 35 & 1 & 0 & 17.4 & 37000 & 0.3 & - & - \\
Geogrid & Elastic & - & - & - & - & - & 0.2 & 4000 & 100 \\
\hline
\end{tabular}

linear behavior is as per modeled by Drucker and Prager ${ }^{[9]}$, with a homogeneous uniform load imposed on foundation. To reach the required accuracy in calculations, uniform load is increased by increments until foundation failure.

The material properties are presented in Table 1 and represent the general standard characteristics of silicon based of poor grading.

For investigation the effect of a certain parameter (shown in Table 1) on the foundation bearing capacity, the values of other parameters are assumed remain constant.

For the numerical analysis, a circular foundation with diameter of $2 m$ and thickness of $0.4 m$ is used. The foundation is placed on the ground surface, on top of the reinforcement soil (embedment depth of zero, $\left.D_{f}=0\right)$.

Investigations were carried out on various parameters such as: (1) The reinforcement placement properties including; the first layer geogrid reinforcement depth ratio from the foundation base $(u / B)$, the geogrid reinforcement thickness ratio $(h / B)$, the number of geogrid reinforcement layers $(N)$, the total reinforced depth ratio $(d / B)$, and the geogrid width ratio $(b / B)$. (2) The reinforced soil properties including; internal angle of friction $(\phi)$, dilation angle of soil $(\psi)$, soil unit weight $(\gamma)$, soil modulus of elasticity $(E)$, and Poisson ratio (V), (3) The reinforcement properties including; reinforcement tensile strength $(T)$, and the elastic normal stiffness of reinforcement $(K)$. (4) The geometric properties of foundation including; the width of foundation $(B)$, and the foundation embedment depth $\left(D_{f}\right)$.

Due to the concentic loading; the ultimate bearing capacity of the foundation $\left(q_{u}\right)$ was calculated based on Terzaghi $^{[17]}$ laboratory and practical observations for vertical loads on unreinforced circular foundations as follows:

$q_{u}=1.3 C N_{C}+\gamma D_{f} N_{q}+0.3 \gamma B N \gamma$

Where, $\gamma=$ unit weight of sand, $B=$ foundation diameter, $D_{f}=$ foundation embedment depth, and $C=$ cohesion of sand. $N_{C}, N_{q}$ and $N_{\gamma}=$ coefficients of bearing capacity which, are calculated from the following equations.

$N_{c}=\left(N_{q}-1\right) \cot \varphi$

$N_{q}=\left(e^{\pi \tan \varphi}\right) \tan ^{2}\left(45+\frac{\varphi}{2}\right)$
$N_{\gamma}=1.5\left(N_{q}-1\right) \tan \varphi$

In equations (5), (6), and (7), $\varphi$ is angle of internal friction of sand. The ultimate bearing capacity of foundation is calculated based on various values of $\varphi$ and compared with finite element analysis results. The first part of the investigation was checking that results from the finite element analysis accurately depicted results achieved when using the Terzaghi model ${ }^{[17]}$. The comparison of results is made, and the finite element analysis is observed to provide an accurate model.

\section{PLACEMENT OF REINFORCEMENT}

Reinforcement Depth - Analysis was undertaken of the variation of $B C R$ versus the reinforcement depth ratio for a circular surface foundation with one layer of reinforcement. The results are shown in Figure 1, noting that the curves have been plotted for various settlement levels. The results indicate that, at the same $u / B$, the $B C R s$ increases as the settlement ratio $(s / B)$ increases. The results also show that; at a $u / B$ ratio of 1.2 the $s / B$ and $B C R s$ stabilise to a relatively constant value.

The results indicate that: (1) if the reinforcement layer is placed at a depth ratio less than 0.2 , the soil mass above the first layer of geogrid is too thin to create enough friction to prevent the reinforcement from pulling out. Hence, in practical cases, it may 


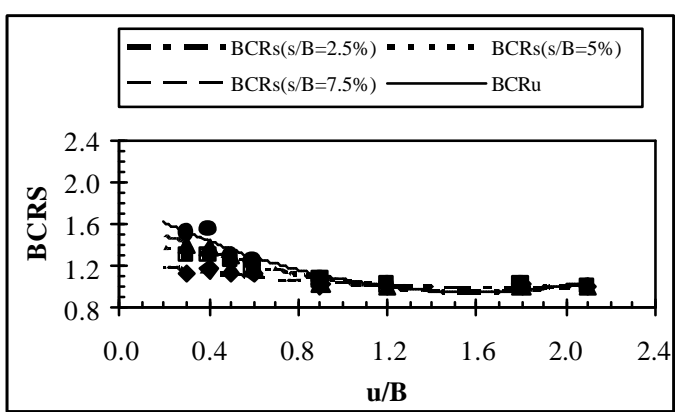

Fig. 1: $B C R$ versus $u / B$ for $N=1, b / B=6, T_{R}=100 \mathrm{kN} / \mathrm{m}$, $K_{R}=4000 \mathrm{kN} / \mathrm{m}$

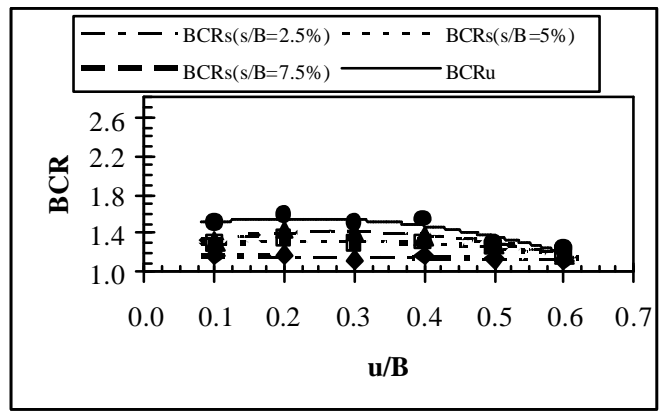

Fig. 2: $B C R$ versus optimum $u / B$ for $N=1, b / B=6$, $T_{R}=100 \mathrm{kN} / \mathrm{m}, K_{R}=4000 \mathrm{kN} / \mathrm{m}$

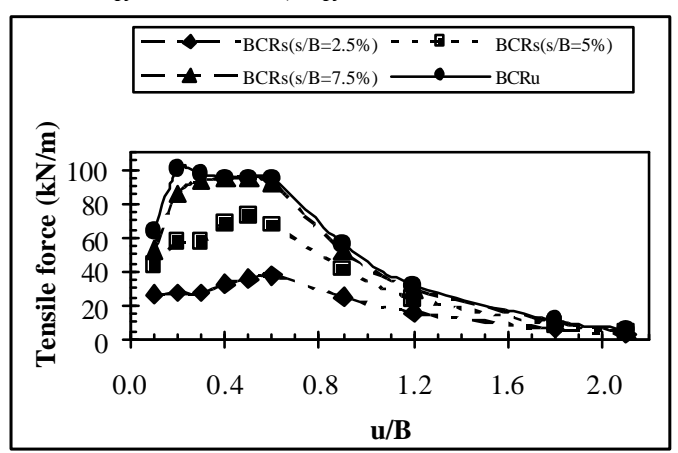

Fig. 3: Tensile force versus $u / B$ for $N=1, b / B=6$, $K_{R}=4000 \mathrm{kN} / \mathrm{m}$

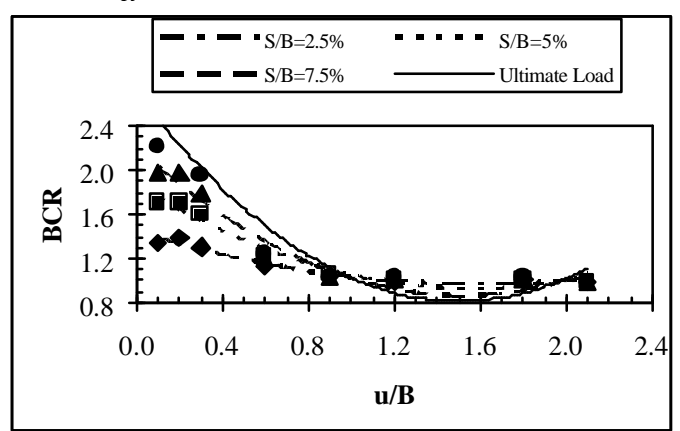

Fig. 4: $B C R$ versus $u / B$ for $N=4, h / B=0.3, b / B=6$, $T_{R}=100 \mathrm{kN} / \mathrm{m}, K_{R}=4000 \mathrm{kN} / \mathrm{m}$

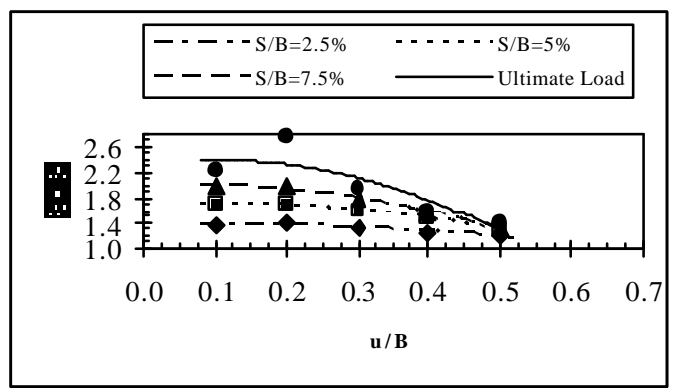

Fig. 5: $B C R$ versus optimum $u / B$ for $N=4, h / B=0.3$, $b / B=6, T_{R}=100 \mathrm{kN} / \mathrm{m}, K_{R}=4000 \mathrm{kN} / \mathrm{m}$

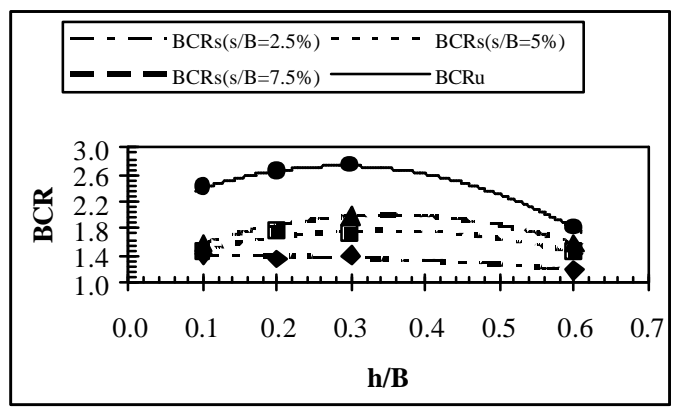

Fig. 6: $B C R$ versus $h / B$ for $N=4, \quad u / B=0.2, \quad b / B=6$, $T_{R}=100 \mathrm{kN} / \mathrm{m}, K_{R}=4000 \mathrm{kN} / \mathrm{m}$

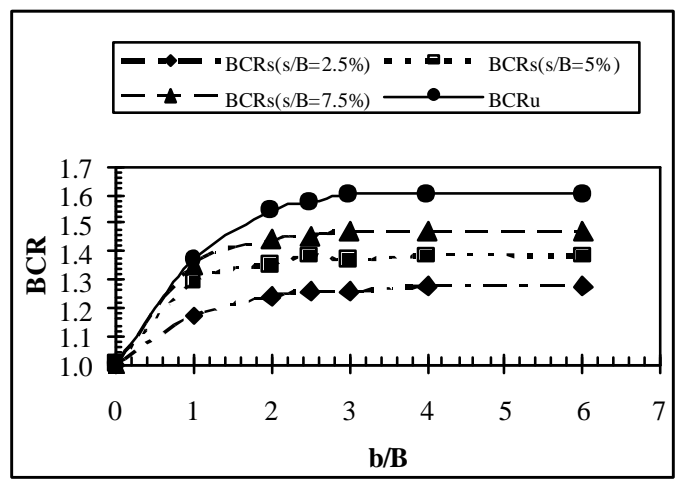

Fig. 7: $B C R$ versus $b / B$ for $N=1, u / B=0.2, T_{R}=100 \mathrm{kN} / \mathrm{m}$,

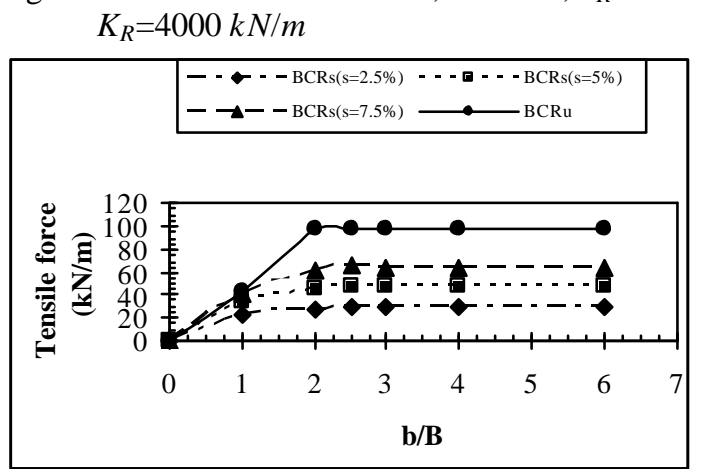

Fig. 8: Variation of $T_{R}$ versus $b / B$ for $N=1, u / B=0.2$, $T_{R}=100 \mathrm{kN} / \mathrm{m}, K_{R}=4000 \mathrm{kN} / \mathrm{m}$ 


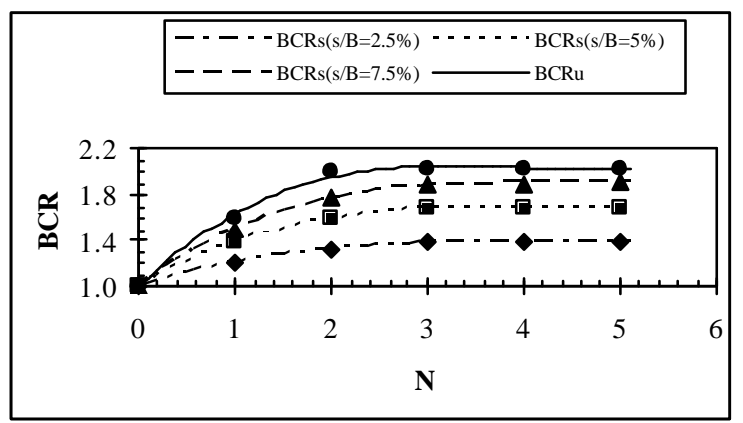

Fig. 9: $B C R$ versus $N$ for $\phi=30^{\circ}, u / B=0.2, h / B=0.3$, $\mathrm{b} / \mathrm{B}=6, T_{R}=100 \mathrm{kN} / \mathrm{m}, K_{R}=4000 \mathrm{kN} / \mathrm{m}$

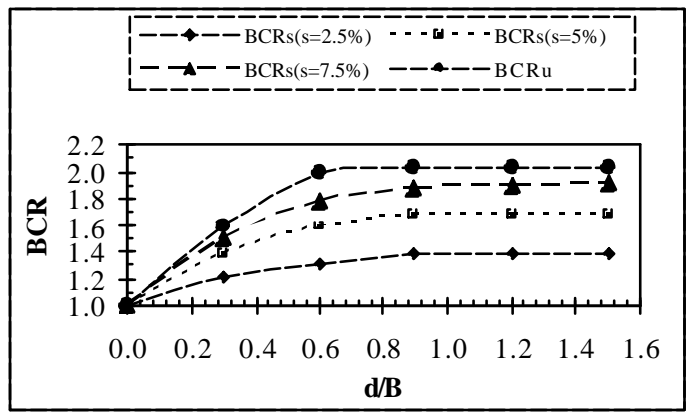

Fig. 10:BCR versus $d / B$ for $\phi=30^{\circ}, u / B=0.2, h / B=0.3$, $b / B=6, T_{R}=100 \mathrm{kN} / \mathrm{m}, K_{R}=4000 \mathrm{kN} / \mathrm{m}$

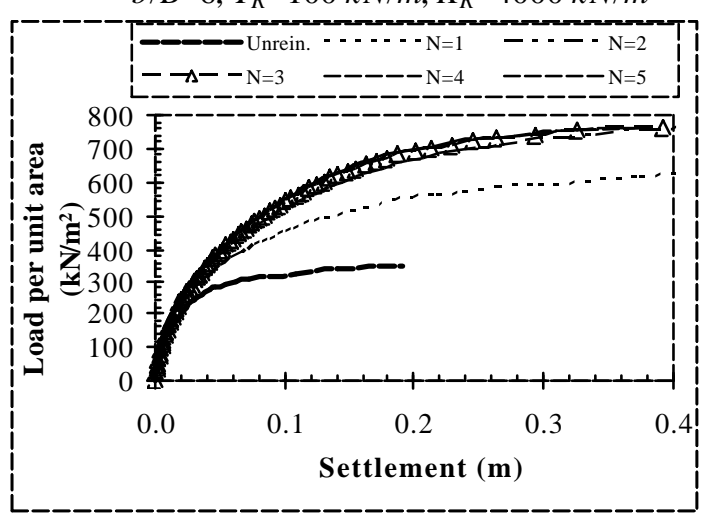

Fig. 11: Load-settlement curves for foundations with and without reinforcement for $u / B=0.2$, $h / B=0.3, b / B=6$

predict the formation of reinforcement failure due to the creation of pressure imposed from wedge failure produced underneath of foundation, (2) For condition $0.2 \leq\left(u_{\prime}^{\prime} B\right)_{o p t .} \leq 0.4$, the load is distributed into the area below the foundation, and creates a proper reinforcement pull-out strength under surcharge pressure. It is in this region that the maximum benefit (load transmission) of the reinforcement can be achieved, and (3) for critical depth ratio, $(u / B)_{\mathrm{cr}}$ of 1.11.2 , the plastic failure zone below the reinforcement layer does not expand and creates the failure above the layer. Hence, placing the reinforcement layer below the critical depth is ineffective. Where $u / B$ greater than $(u / B)_{\mathrm{cr}}$, the reinforcement layer acts as a semi-rigid plane, and the soil wedge failure develops above reinforcement layer. Extending the $B C R$ versus depth ratio curve, for $u / B$ greater than $(u / B)_{\mathrm{cr}}$, it can be observed that, for $u_{l}^{\prime} B \approx 2$, the bearing capacity ratio will be $\approx 1$. This value is consistent with laboratory data obtained by Pfeifle and Das ${ }^{[10]}$.

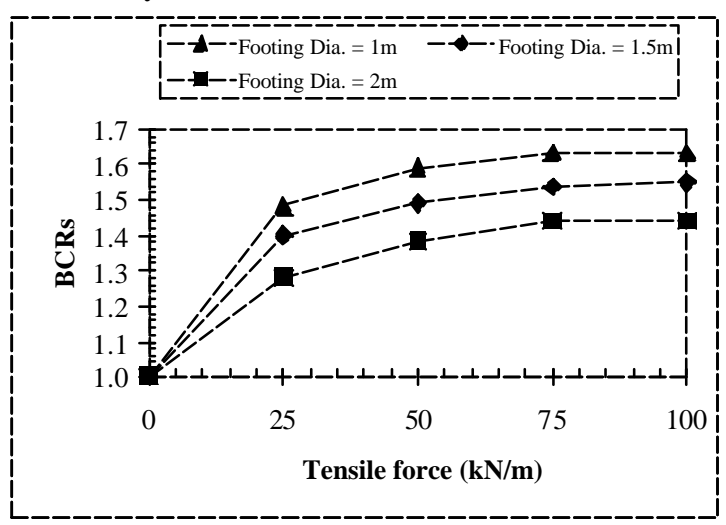

Fig. 12: $B C R s$ at $s / B=\% 7.5$ versus $T_{R}$ for $N=1, u / B=0.2$, $\mathrm{b} / \mathrm{B}=6, K_{R}=4000 \mathrm{kN} / \mathrm{m}$

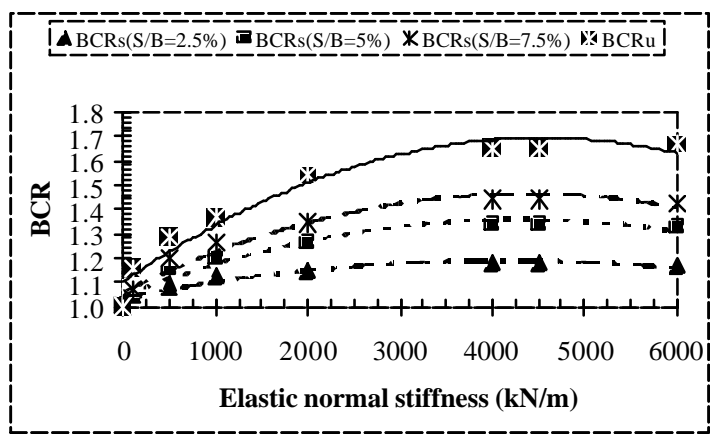

Fig. 13:BCR versus elastic normal stiffness for $N=1$, $u / B=0.2, b / B=6, K_{R}=4000 \mathrm{kN} / \mathrm{m}$

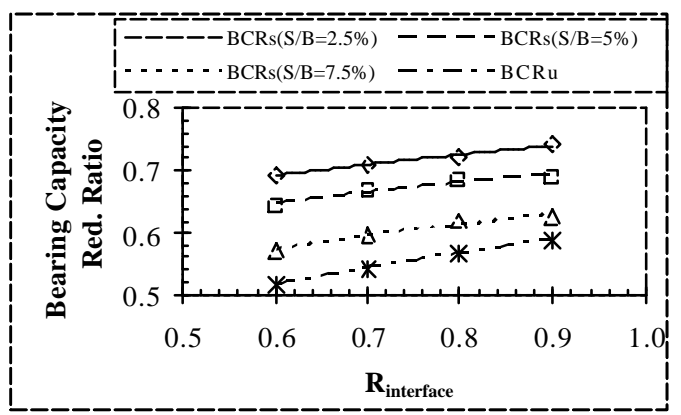

Fig. 14: Bearing capacity reduction ratio versus $R_{\text {interface }}$ for $N=1, u / B=0.2, b / B=6, T_{R}=100 \mathrm{kN} / \mathrm{m}$, $K_{R}=4000 \mathrm{kN} / \mathrm{m}$ 


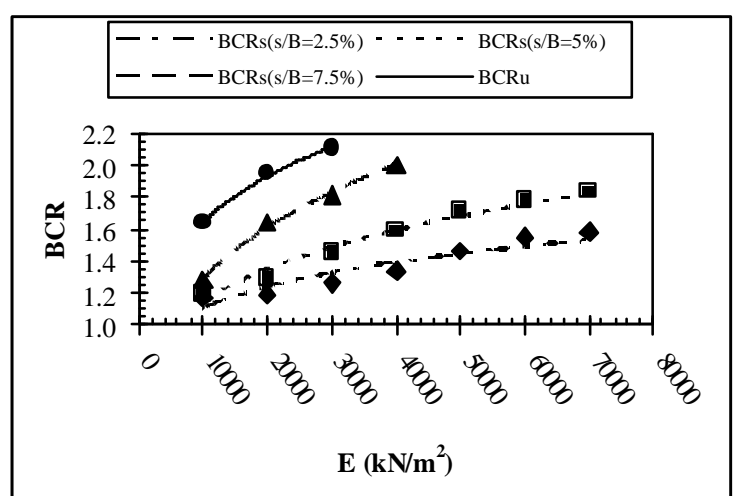

Fig. 15: $B C R$ versus sand modulus of elasticity for $N=1, u / B=0.2, b / B=6, T_{R}=100 \mathrm{kN} / \mathrm{m}, K_{\mathrm{R}}=4000$ $k N / m$

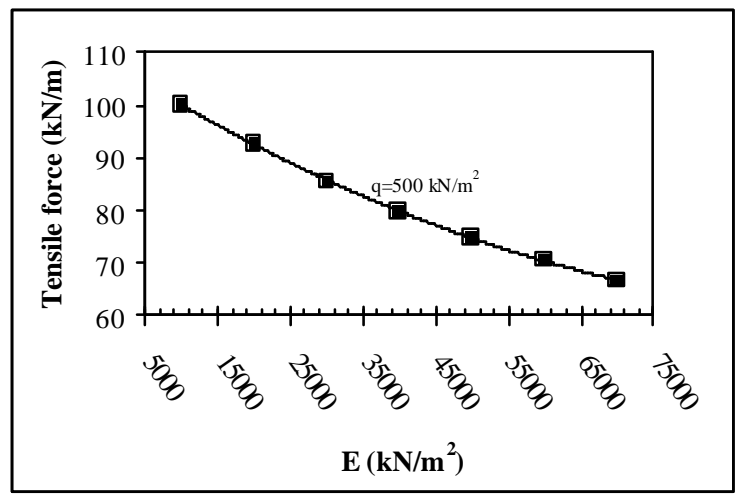

Fig. 16: Tensile force versus sand modulus of elasticity for $N=1, u / B=0.2, b / B=6, K_{R}=4000 \mathrm{kN} / \mathrm{m}$

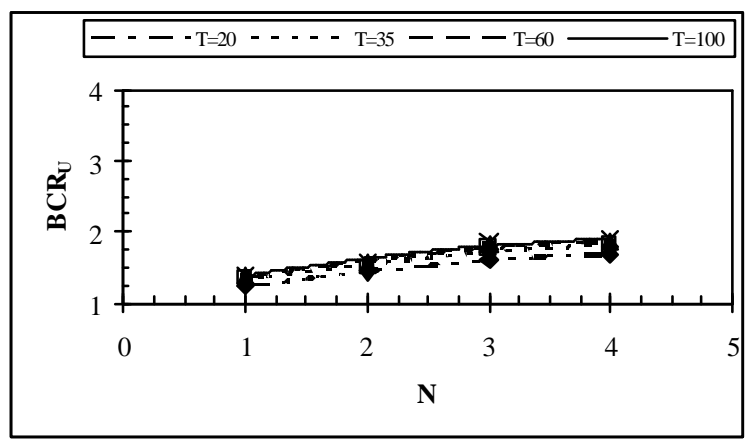

Fig. 17a: Design curve models for multiple reinforcement layer for $b / B=1, u / B=0.2$, $h / B=0.3$, footing width $=2 m$, min. friction angle $=30^{\circ}$

The optimal $u / B$ is shown in Figure 2. The numerical analysis shows that; the maximum $B C R$ is achieved at a depth ratio of 0.2 . It also shows that the BCRs increases with increasing settlement.

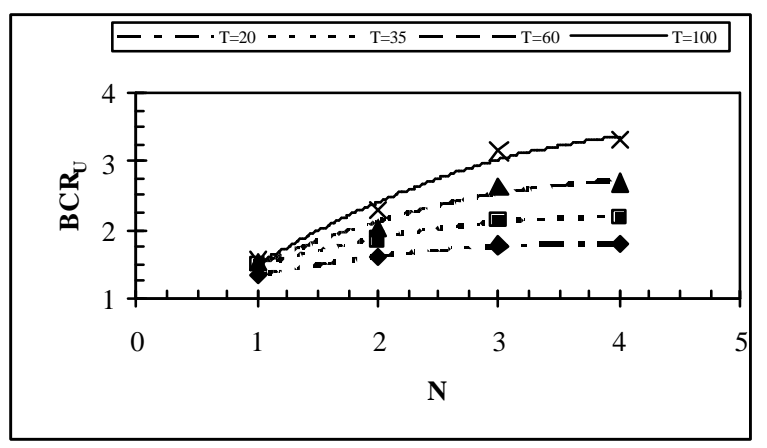

Fig. 17b: Design curve models for multiple reinforcement layer for $b / B=2.5, u / B=0.2, h / B=0.3$, footing width $=2 \mathrm{~m}$, min. friction angle $=30^{\circ}$

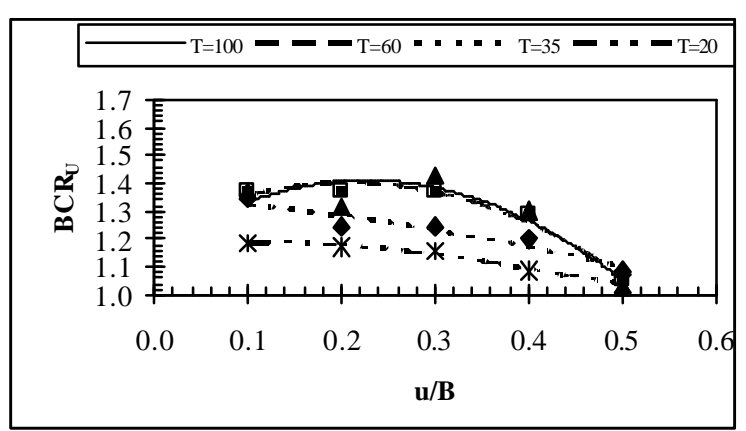

Fig. 18a: Design curve models for one layer reinforcement for $b / B=2, \quad N=1$, footing width $=2 \mathrm{~m}$, min. friction angle $=30^{\circ}$

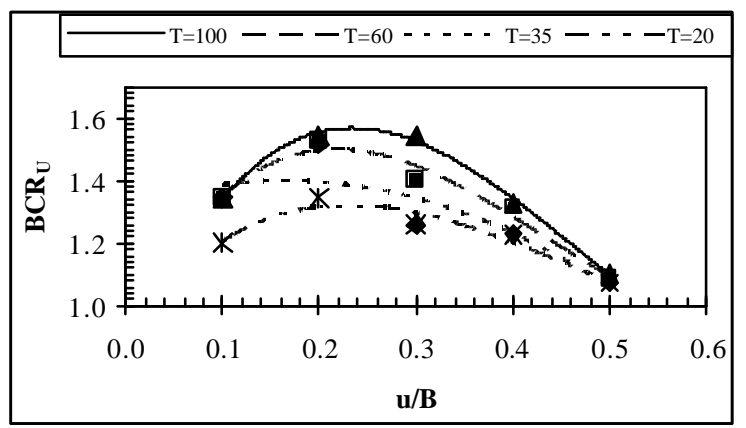

Fig. 18b: Design curve models for one layer reinforcement for $b / B=3, N=1$, footing width $=2 \mathrm{~m}$, min. friction angle $=30^{\circ}$

The results of an analysi of tensile force versus $u / B$ for various settlement levels is shown in Figure 3. The results indicate that; the tensile force increases up to the depth ratio of almost 0.6 , and then, drop rapidly to depth ratio of 1.2 before levelling out achieving a more gradual decrease. As $u / B$ approaches 2 the 
reinforcement tensile force approaches zero. This may indicate that; the stress bubbles do not penetrate further than $2 B$ below the foundation base.

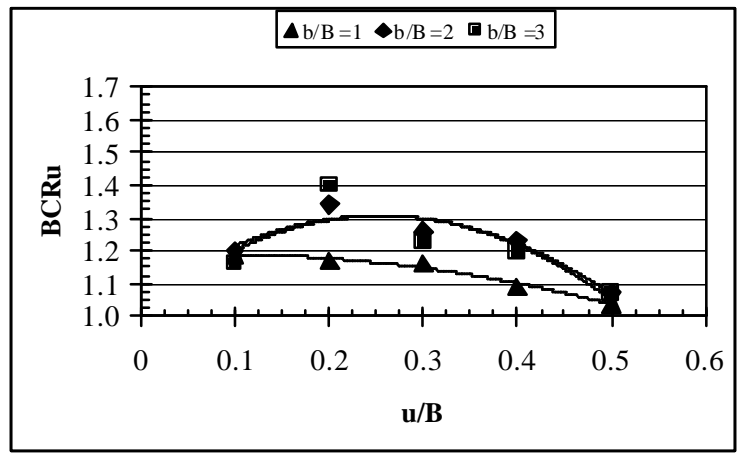

Fig. 19a: Design curve models for \&ogrid reinforcement for $T_{R}=20 \mathrm{kN} / \mathrm{m}, N=1$, footing width $=2 \mathrm{~m}$, min. friction angle $=30^{\circ}$

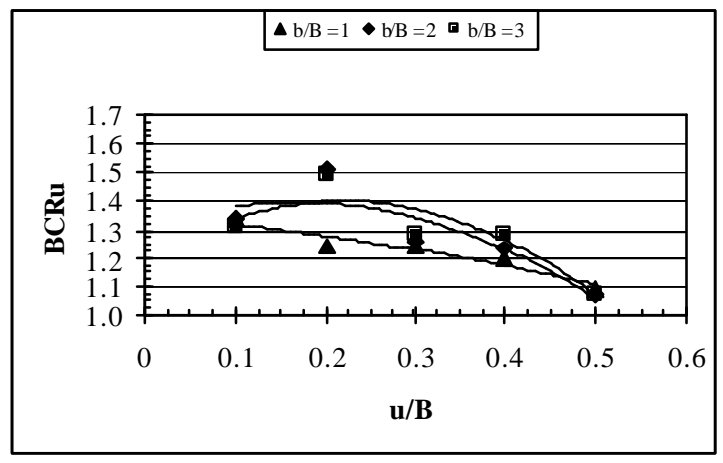

Fig. 19b: Design curve models for geogrid reinforcement for $T_{R}=35 \mathrm{kN} / \mathrm{m}, N=1$, footing width $=2 \mathrm{~m}, \mathrm{~min}$. friction angle $=30^{\circ}$

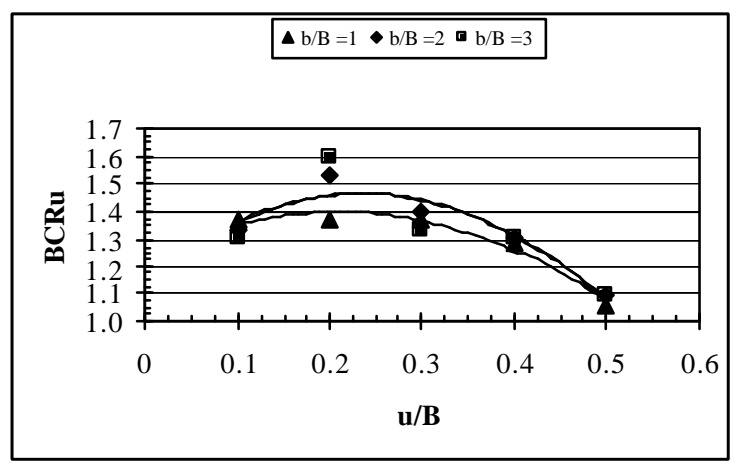

Fig. 19c: Design curve models for geogrid reinforcement for $T_{R}=60 \mathrm{kN} / \mathrm{m}, N=1$, footing width $=2 \mathrm{~m}, \mathrm{~min}$. friction angle $=30^{\circ}$

The Effect of Multiple Layers of Reinforcement: The results of numerical assessment of multiple layers (four layers in this example) of geogrid reinforcement are shown in Figures 4 and 5. The plot curves indicate that; the $B C R$ reaches a maximum (for various settlement levels) at an optimum depth ratio of 0.2. While Figure 4 shows decrease in $B C R$ with increase in depth ratio, the variation of $B C R$ for $(u / B) \leq 0.3$ is insignificant. Also, when the depth ratio increases above 0.9; the variation of $B C R$ with differing settlement levels is insignificant. Hence, the critical depth ratio can be selected as $\approx 0.9$. These results confirm the findings by $\operatorname{Sing}^{[11]}$, which were based on the study of square footings on sand reinforced with mild steel grids (optimum depth ratio was about 0.25 ). However, the results are in contrast with reports of other researches ${ }^{[7,12,13]}$, which, most likely is due to difference in material properties and the geometric dimensions of the foundation and reinforcement. Hence, it may be concluded that; reporting a single value of $u / B$ for optimum bearing capacity of geogrid reinforced soil is flawed as reported by other researchers such as; Adams and Colin ${ }^{[2]}$, Yetimuglu et al. ${ }^{[4]}$, and Guido et al. ${ }^{[8]}$.

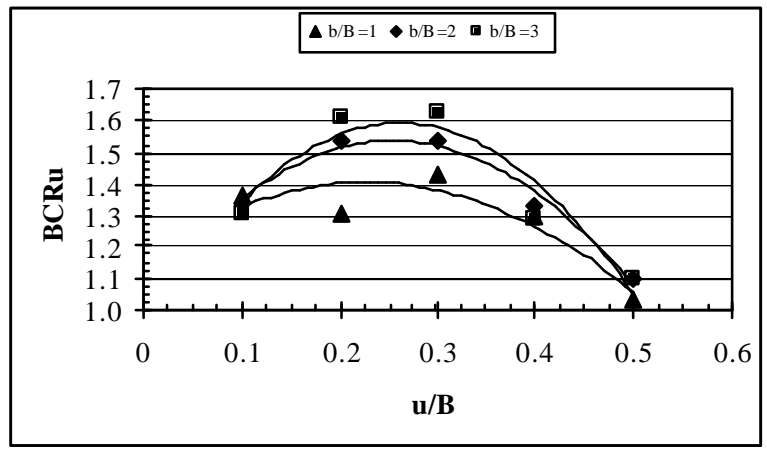

Fig. 19d: Design curve models for geogrid reinforcement for $T_{R}=100 \mathrm{kN} / \mathrm{m}, N=1$, footing width $=2 \mathrm{~m}$, min. friction angle $=30^{\circ}$

Spacing of Reinforcement: The results of the assessment of multiple layers of reinforcement also showed that; there exists an optimum verical spacing distance (or height ratio $h / B$ ) (or a range of values) between the reinforcement layers. The variation of $B C R$ versus $h / B$ for various settlement levels and four layers of reinforced sand is shown in Figure 6. In this case, the optimum value for $h / B$ is about 0.3 for aproximately for all settlement levels. This value is slightly higher than $0.15-0.25$ suggested by others ${ }^{[4,11]}$. Furthermore, Guido et al. ${ }^{[7]}$, and Akinmusuru and Akinbolade ${ }^{[12]}$ reported that, as the vertical spacing increases, the $B C R$ value decreases accordingly. Guido et al. ${ }^{[13]}$, indicated that, although the $B C R$ value decreased with increasing vertical spacing, the trend of $B C R$ variation with 
vertical spacing was different for different geogrids. However, the disagreement with the findings reported ${ }^{[7}$, $12,13]$ may be due to the difference in the material properties and the geometric dimensions of the foundation and geogrid used in the present study.

The influece of vertical spacing between the reinforcement layers on $B C R$ may also be related to the variation of applied normal forces on reinforcement, as, with an increase in depth below the foundation base; the friction forces, and thus the reinforcement pull-out resistance, decrease accordingly. As shown in figure 6 , for the case of $h / B<0.5$, the wedge shear failure penetrates into the reinforcement zone; provoking the reinforcement, and resulting in an increase in bearing capacity.

Reinforcement Width: The variation of $B C R$ versus reinforcement width ratio $(b / B)$ for various settlement levels and conditions is shown in Figure 7. For a given settlement level; $B C R$ increases with $b / B$. At $b / B=3$, the curve tends to convex upward and levels off to a constant value. Hence, $b / B=3$ can be considered the optimum reinforcement width ratio $\left[(b / B)_{\text {opt }}\right]$. The numerical analysis showed that the value of $(b / B)_{\text {opt }}=3$ remains the same for multiple reinforcement layers. This result is slightly higher than that reported by Guido et al. ${ }^{[8]}$, who obtained $(b / B)_{\mathrm{opt}}=2.5$ for square foundations.

The mechanism of the reinforced soil system can be described as; with increase in reinforcement length; the friction forces derived from imposed normal forces on a unit length of reinforcement increases; which results in an increase in the reinforcement friction strength. Furthermore, below the foundation base, there is a zone of shear deformation at the interface between zones 1 and 2 . The creation of an effective tensile strength in the reinforcement requires; a portion of the reinforcement to be anchored beyond this zone to develop sufficient friction to resist pull-out.

Curves plotting reinforcement tensile force versus $b / B$ for various settlement levels are shown in Figure 8 . The results indicate that; at $b / B=2$ to 2.5 , the tensile force reaches a maximum and levels off to a constant value.

Plots of $B C R_{u} / B C R$, with averages extracted from Figure 7 versus $b / B$ indicates that; for all values of $b / B$, the $B C R_{s} \approx 0.80 B C R_{u}$.

Effects of Multiple Layers of Reinforcement: The effect of the number of reinforcement layers on bearing capacity ratio $(B C R)$ and tensile force $T_{R}$, at various depths, illustrates that; for a given settlement level; the $B C R$ increases with increasing layers of reinforcement. Furthermore, it appears that, the variation of the number of reinforcement layers $(N)$ has a dramatic effect on bearing capacity (moreso that the variation of other parameters).

The plots of $B C R_{u}$ and $B C R_{s}$ versus the number of layers of reinforcements $(N)$ is presented in Figure 9. Results indicate that; for a given settlement level, the plot curves tend to convex upward and level off to a constant value for $N \geq 3$. This result is equivalent to that of reinforcemernt depth ratio, $d / B=0.9 \approx 1$ shown in Figure 10. It appears that; the increase in $B C R$ for depth beyond $0.9 \approx 1 B$ is not significant, or in practical terms, placing the reinforcement at a depth greater than $B$; does not improve the bearing capacity.

The load-settlement curve for the circular foundation supported by differing numbers of reinforcement layers is shown in Figure 11. The results show that; the curves for $N=3,4$, and 5 coincide with each other. This suggests that the optimum number of layers of reinforcement, $N=3$. This confirm the works of Akinmusuru and Akinbolade ${ }^{[12]}$, and Guido et al. ${ }^{[8]}$, who reported that; the rate of increase in $B C R$ would decrease beyond 3 layers of reinforcement. However, the results disagree with the findings reported by Yetimoglu et al. ${ }^{[4]}$, which suggested that the optimal number of reinforcement layers, $N=4$, corresponding to a reinforcement depoth of $1.5 \mathrm{~B}$; Omar et al. ${ }^{[14]}$, and Booshehrian and Hatef ${ }^{[15]}$ who also found that the optimum number of layers of reinforcement, $N=4$. The differences in results may be due to the differences in the material properties and the geometric dimensions of the geogrid they used in their studies.

\section{Generation of Tensile Forces in the Reinforcement:} The variation of tensile force with the reinforcement embedment depth ratio $(z / B)$ shows that, for a given embedment depth ratio, all layers of reinforcement coincide with each other. This means, that the optimum embedment depth ratio for any number of layers of reinforcement is the same. The results indicate that; the tensile forces generated at reinforcement embedment depth ratio of 1.5 , is $20 \mathrm{kN} / \mathrm{m}$. If the right end of the curve is extrapolated, it intersects the $x$-axis at $(z / B) \approx 2$ which; represents the reinforcement tensile force of $T \approx 0$. If the Bossinesque theory ( $\operatorname{Das}^{[16]}$ ) is used to estimate the soil stress below a flexible pavement under uniform bading, the following results can be derived for circular foundations: 
Am. J. Applied Sci., 5 (4): 355-368, 2008

$\begin{gathered}\Delta P \approx 0.286 q \\ \text { foundation) }\end{gathered} \quad$ (for $\quad d / B \approx 2.4 \quad$ below center of
$\begin{gathered}\Delta P \approx 0.087 q \\ \text { foundation) }\end{gathered} \quad$ (for $\quad d / B \approx 5.1 \quad$ below center $\quad$ of

Where: $\Delta p=$ pressure increment on foundation

and, $q=$ load per unit area of the foundation.

The results of using the Bossinesque theory show that the optimal reinforcement depth is where $\Delta p / q \approx 0.28$.

The Variation of $B C R_{u} / B C R_{s}$ versus number of layers of reinforcement $(N)$ indicates that, inspite of some scatter in results, the linear correlation indicates that; for any number of layers of reinforcement, the $B C R_{S} \approx 0.80 B C R_{u}$. Based on stress distribution below the circular foundations, it appears that; with an increase in reinforcement depth ratio; the normal force decreases and subsequently; the friction between the soil and reinforcement decrease. Thus, placing the reinforcement at a lower embedment depth; does not increase the bearing capacity as friction forces for circular foundations at $2 B$ approaches zero.

Overall the parameter improvement gained by using multiple layers of reinforcerment may be attributable to the increase in shearing strength and the geogrid-sand system acts as a composit material and prevents the distribution of soil wedge failure below the foundations base.

Reinforcement Effect on Settlement: To evaluate the effects of reinforcement on the deformation of loadsettlement curves for foundations supported by sand with, and without, reinforcement; Figure 11 can be used. The load-settlement curves indicate that; the type of failures differ between the reinforced, and unreinforced, cases. The load-settlement curve slope for the unreinforced foundation experiences relatively dramatic failure (i.e. levelling of the curve) at a settlement of $0.1 \mathrm{~m}$. In soil mechanics this type of failure is referred to as general shear failure. In contrast, the foundation with multiple layers of reinforcement experiences gradual failure, as illustrated by the gradual levelling of the curve. This type of failure is called local shear failure.

The mechanism of interaction between the soil and reinforcement occur in such a way that; with transferral of stress from the soil to the reinforcement, the increase in friction and passive strengths against pulling out result in an improvement of the bearing capacity of the foundation. In this example the use of reinforcement increases the ultimate bearing capacity over the unreinforced foundation by up to $300 \%$ $\left(1.5 \leq B C R_{u} \leq 3\right)$, which; is equivalent in this example of settlements of 100 to $400 \mathrm{~mm}$. This level of settlement would not be acceptable in construction practice, therefore the bearing capacity with controlled settlement can be limited to $B C R_{s}=0.8 B C R_{u}$. When limiting settlement (e.g. $\leq \% 2.5$ ) the reinforcement acts to immediately, and over the long term, decreases the soil strain which; results in the improvement to the soil properties (refer to Figure 11).

\section{THE REINFORCEMENT PROPERTIES}

The investigation of the reinforcement properties of tensile strength $\left(T_{R}\right)$ and elastic normal stiffness of reinforcement $\left(K_{R}\right)$ are critical components in understanding the contribution of the reinforcement to the strengthening of the foundation system.

Reinforcement Tensile Strength: The varation of bearing capacity ratio $(B C R)$ of foundations with diameters of $1.0 \mathrm{~m}, 1.5 \mathrm{~m}$ and $2.0 \mathrm{~m}$ versus reinforcement tensile stress for one layer of reinforcement was analysed and the results are shown in Figure 12. The results indicate that; with a given foundation diameter; and an increase in the allowable tensile force from 25 $\mathrm{kN} / \mathrm{m}$ to $100 \mathrm{kN} / \mathrm{m}$, the $B C R$ increases. At a tensile force of approximately $75 \mathrm{kN} / \mathrm{m}$; the increase in $B C R$ levels off to (an almost) constant value for all foundations diameters tested. The results suggest that in practical works, and for foundations with "ordinary" dimentions; increasing the tensile strength of the reinforcement above a certain level does necessarily result in an increase $B C R$.

Reinforcement Elastic Normal Stiffness: The manufactured elastic normal stiffness of geogrids usually varies from $100 \mathrm{kN} / \mathrm{m}$ to $6000 \mathrm{kN} / \mathrm{m}$. The behavior of the reinforced soil supporting the foundation is dependent on the value of the elastic normal stiffness. The variation of $B C R$ versus reinforcement elastic normal stiffness for various settlement levels is shown in Figure 13. The results indicate that; beyond a specific value, the elastic normal stiffness does not improve the bearing capacity of the foundation effectively. Figure 13 suggests that; the optimum value for elastic normal stiffness is about $4000 \mathrm{kN} / \mathrm{m}$. This is in contrast to $1000 \mathrm{kN} / \mathrm{m}$ determined by Yetimoglu et $\mathrm{al}^{[4]}$ (who worked on rectangular 
footings). The difference in results is most likely due to differences in the geogrid material properties and the geometric dimensions of the geogrid used.

The variation of tensile force versus elastic normal stiffness indicates that, at a given settlement level; the curve tends to take a convex upward shape and levels off at elastic normal stiffness of $4000 \mathrm{kN} / \mathrm{m}$. Hence, it seems that, the maximum strength of reinforcement is used at this point.

Development of Friction Between Reinforcement and Soil: Due to the difference in embankment gradation of the soil supporting the foundation and the size of the voids in the geogrid mesh it is physically impossible to achieve $100 \%$ friction at the soil / geogrid interface. The actual level of friction development is thus an important parameter and is determined through the pull-out test. For the purposes of this investigation the decreased in friction between the soil and reinforcement is denoted as a coefficient ratio of the angle of internal friction $\left(R_{\text {interface }}=\delta / \varphi\right)$. Also, the effect of decreased bearing capacity resulting from the decreased friction development, is denoted as a nondimensional decreased bearing capacity coefficient which; is the ratio of the bearing capacity of reinforced foundation $1<R_{\text {interface }}=1$.

The variation of the two dimensionless parameters, the bearing capacity reduction ratio versus coefficient of internal angle of friction ratio is plotted in Figure 14. In this example, the value of $R_{\text {interface }}$ is estimated between 0.6 to 0.9 . The results indicate that; with a given settlement level, and an increase in $R_{\text {interface }}$, the reduction coefficient of settlement increases. This condition is similar for all settlement levels. The variation of (created) normal and shear strengths in the reinforcement verses $R_{\text {interface }}$ shows that; with $R_{\text {interface }}$ $\approx 0.6$; the effective normal stress is almost three fold of the shearing stress, while with increasing in $R_{\text {interface, }}$ the differences between both stresses decrease in such a way that; at $R_{\text {interface }} \approx 0.9$, the difference is about $60 \%$.

Soil Properties: In reinforced soil foundations granular soils (silicous sands) are used to replace the existing soil and form part of the reinforced soil system due to their beneficial, and generally consistent, properties of durability, good drainage, constructability and increased interaction between the soil and reinforcement. The granular soil used is considered to well graded. The parameters evaluated as part of this investigation include internal angle of friction $(\phi)$, modulus of elasticity $(E)$, unit weight $(\gamma)$, dilation angle $(\psi)$, and Poisson ratio $(\nu)$ (based on AASHTO specifications) is used.

Friction Angle: The sand angle of internal friction $(\phi)$ varied from 24 to 46 degrees and its effect on foundation behavior, bearing capacity ratio, and reinforcement created tensile forces was evaluated.

The variation of load per unit area versus internal angle of friction $(f)$ for various settlement levels indicates that; with a given settlement level, an increase in $f$ results in a corresponding increase in the foundation load bearing capacity. The results also show that; an increase in the level of settlement, results in an increase in the load bearing capacity. Extrapolating the initial, and final, results using tangents gives point with minimum curvature, or optimal internal angle of friction $f=38$ degree.

In order to achieve an internal angle of friction of 38 to 40 degrees, the soil requires a USCS classification $G W$ (well graded gravel) or $G P$ (poorly graded gravel) and relative compaction above $85 \%$ (as defined by AASHTO). However, the soil particle size is limited by the size of the geogrid mesh opening. As the soil particles increase in size the movement of the particles through the geogrid opening is reduced, relative friction reduces and the pull-out strength of the reinforcement decreases, thus decreasing the ultimate bearing capacity of the foundation. Also, based on geosynthetic manufacturer's recommendations for using a soil type such as $G P$, the bearing capacity of reinforced soil structures decreases by up to $10 \%$ due to the mechanical interference during the installation of the geogrid. Thus it is suggested that the optimal internal angle of friction is between 35 to 38 degrees.

\section{Reinforcement Tensile Strength Versas Soil Internal} Angle of Friction: The variation of maximum reinforcement tensile force versus the soil internal angle of friction is drawn. The investigation used an applied load on the foundation surface of $500 \mathrm{kN} / \mathrm{m}^{2}$. The results indicate that; with increasing $f$, the resultant reinforcement tensile force decreases rapidly to an internal angle of friction of approximately 36 degrees and then levels off to an almost constant value. This is explained by the fact that the weaker the soil the more the load is carried by the reinforcement, however, above a certain soil strength the soil particles are able to carry more of the load. 
Based on the results achieved above, the reinforced soil can be economically designed. By increasing the strength of the soil a lower geogrid tensile strength can be used. Cost savings can be achieved as generally the sourcing, placement and compaction of soils is more cost effective than expensive geosynthetics.

In unreinforced foundations increasing the dilation angle (?) from zero to ultimate $f$ results in a corresponding increase in the bearing capacity. Even though, in loose soils; the increase in volume (dilation) is not observable; for $f$ less than, or equal to, the average $f$ (e.g. $\phi<27^{\circ}$ ), using the ? is not physically justified. However, for higher values of $f$, the value of ? is limited to a maximum of $f / 3$ or $f / 2$. In this research the value of ? was estimated to be between 4 to 16 degrees and; its effect on reinforced soil beneath the foundation base was evaluated.

The varation of $B C R$ versus dilatancy angle, ? shows that, for a given settlement level, with increase in ?, the $B C R$ increases. Also the plots curves indicate that; at a given ?, with increase in settlement level, the $B C R$ increases accordingly. However, the increase in $B C R$ is very moderate up to 8 degrees but for ? $\geq 8$ degrees, the increase of $B C R$ is much steep.

The investigation of surcharge load per unit area versus the unit weight of the sand (density) for various settlement levels indicates that; at a given settlement level the increase in unit weight of the soil results in an increase in the foundation bearing capacity. Also the resultant curve indicates that; at a given soil unit weight, an increase in settlement level, the bearing capacity increases. Overall however, the increase in bearing capacity with increase in unit weight is insignificant.

The variation of reinforcement tensile force versus sand unit weight shows that; at a given unit weight, with increase in the level of settlement, the reinforcement tensile force increases (settlement/increase in tensile force) $2.5 \% / 107 \%$, $5 \% / 44 \%$, and $7.5 \% / 21 \%$. This result suggests that increasing the settlement level ratio increases the tensile force but the ratio of increase in tensile force reduces as settlement level increases. Overall however, increasing the sand unit weight does not, significantly change the reinforcement tensile force.

The variation of $B C R_{S} / B C R_{u}$ versus sand unit weight for various settlement levels indicates that, at a given unit weight, the ratio of $B C R_{S} / B C R_{u}$ increases with increasing levels of settlement. The plot curves also indicate that; the $B C R_{S} / B C R_{u}$ decreases slightly with increase in soil unit weight. The results of the investigation shows that the average bearing capacity / settlement levels relationship is: $70 \% / 2.5 \%, 80 \% / 5 \%$, and $86 \% / 7.5 \%$ respectively.

The variation of $B C R$ versus modulus of elasticity $(E)$ for sand for various settlement levels is shown in Figure 15. The results show that; increasing $E$ increases the $B C R$ values. The plot curves also indicate that; given the same $E$ an increase in the settlement level results in an increase $B C R$. Also, at a given $E$, slope of the curves become much steeper as the settlement level increase.

The investigation into the variation of reinforcement tensile force versus $E$ (at constant load) is shown in Figure 16. The results show that; (with the application of a constant load of $500 \mathrm{kN} / \mathrm{m}^{2}$ ); the reinforcement tensile force decreases with increase in $E$. The increase in $E$ can be attributed to the increase in the sand stiffness; (i.e. Greater load carrying capacity) causing the tensile force to decrease. Furthermore, increase in the soil stiffness; causes a decrease in deformation (settlement) and; related decrease in the level of strain experienced by the reinforcement. Thus, with increasing $E$ the activation of the reinforcement is reduced, resulting in a decrease in the generation of tensile force.

The Poisson ratio ( $V$ ) which; is defined as the ratio of unit lateral strain to unit longitudinal strain has considerable influence on bearing capacity ratio $(B C R)$. The results of the investigation into the variation of Poisson ratio versus $B C R$ shows that; at a given Poisson ratio, the $B C R$ increases with increase in settlement. The curve plots also indicate that increasing the Poisson ratio results in a corresponding increase in the $B C R$.

The Geometric Properties Of Circular Foundations: To investigate the effects of foundation dimensions and the foundation embedment depth; investigation was undertaken varying these parameters in the numerical model and comparing the results against changes in $B C R$.

The variation of $B C R$ versus foundation diameter $(B)$ at various settlement levels indicates that, at a given diameter, the $B C R$ increases with increase in the settlement level and; at larger diameters; the rate of increase is higher. Also the plot curves indicate that increasing the foundation diameter resulted in a decrease in $B C R$ up to foundation diameter of $1.5 \mathrm{~m}$ and then, at which point the decrease in $B C R$ levelled off. 
The reason seems to be that; with increase in dimension of foundation, the normal force which creates friction strength between soil and reinforcement is decreased. Hence, the reinforcement tensile force decreases and the reinforcement is not activated bringing it in line with the unreinforced soil

The variation of $B C R$ for a settlement ratio $(s / B)$ of $7.5 \%$ for varying tensile forces versus foundation diameter shows that; at a given diameter as the tensile force increases so does the $B C R$. The plot curves also indicate that, with increase in diameter and at a given tensile force, the $B C R$ decreases with steep downward slope from diameter $0.5 \mathrm{~m}$ to diameter $1.5 \mathrm{~m}$, at which point the rate decreases. This shows similar behavior to the laboratory works of Das and Omar ${ }^{[14]}$ who worked on strip foundations.

The variation of $B C R$ versus embedment depth ratio $\left(D_{f} / B\right)$ for various settlement levels indicates that, at a given $D_{f} / B$, with increase in settlement level, the $B C R$ value increases. The results also indicate that, for a given settlement level, with increase in $D_{f} / B$, the $B C R$ values increase correspondingly.

Modelling Curves: Based on the results achieved in this study a number of design curves have been developed to assist with the estimation (design) of field bearing capacity of shallow foundations supported by geogrid reinforced soil. Keeping in mind the settlement limitations in real space, the curves have been developed for normal settlement levels up to a settlement ratio $(s / B)$ of $2.5 \%$. The new models are presented in Figures $17 a, 17 b, 18 a$ to $18 c$ and 19 a to 19d. The internal angle of friction of 30 degrees has been used and the results are based on the ultimate bearing capacity ratio $\left(B C R_{U}\right)$. This means that for any design with a controlling settlement condition; the $B C R_{U}$ can be used. Furthermore, based on analytical results obtained in this study; the relationship $B C R_{s} \approx 0.80 B C R_{u}$ can be used for all presented models.

Model curves plotted in figures $36 a$ and $36 b$ show the variation of $B C R_{u}$ versus number of geogrid reinforcement layers for various tensile forces and for width ratios $(b / B)$ of 1 and 2.5 . These models indicate that; with increasing the width ratio towards its optimum value and with increasing tensile forces, the $B C R_{u}$ increases.

Figures $19 a$ and $19 b$ show the variation of $B C R_{u}$ versus depth ratio to the upper layer of geogrid $(u / B)$ for various tensile force and for width ratios $(b / B)$ of 2 and 3. These models indicate that; with increasing the $b / B$, the value of $B C R_{u}$ will increase accordingly, and for a certain optimum depth ratio, the maximum $B C R_{u}$ can be determined.

The variation of $B C R_{u}$ versus $u / B$ for reinforcement width ratios of 1,2 , and 3 is shown in figures $19 a$ to $19 d$. From these models and for optimum $u / B$ and $b / B$; the ultimate bearing capacity will be determined.

\section{RESULTS AND DISCUSSIONS}

This study was carried out to investigate and analyse the parameters that govern the behavior of circular foundations supported by geogrid reinforced sand. The effects of the reinforcement placing properties, soil properties, reinforcement properties, and the geometric properties of the circular foundations were investigated. This paper presents the results of a two dimentional, non-linear, finite element in planestain condition analyses, and a comparison of the results with other researches. Base on the numerical model investigation, the following conclusions can be drawn:

\section{One layer of geogrid reinforcement:}

1. For $u / B$ less than 0.2 ; the soil mass above the geogrid layer does not create enough friction strength to prevent the reinforcement from pulling out and may cause reinforcement failure

2. The $B C R$ value reached to its maximum at an optimum $u / B$ of 0.1 to 0.3 and the critical depth ratio was $\approx 0.9$ (which; is consistent with rectangular footing as reported by Yetimoglu et al., 1994)

3. At $u / B \approx 2$; the reinforcement tensile force reaches to an insignificant value. This may indicate that; the stress bubbles do not penetrate further than $2 B$ below the foundation base

4. The optimum $b / B$ found was 3 . This value is the same for multiple reinforcement layers and is greater than that reported by Guido et al., 1985, who optained the value of 2.5 for square footings

5. It was found that; choosing a more rigid reinforcement does not always lead to a better results in terms of $B C R$. The optimal (including a consideration for economics) allowable design stress for the reinforcement is $100 \mathrm{kN} / \mathrm{m}$. Also, the applied load on foundations supported by reinforced soil is a function of friction strength between the soil, the reinforcement, and the reinforcement tensile strength

6. The once the reinforcement elastic normal stiffness exceeds a certain value it does not effectively improve the bearing capacity of the circular 
foundation. The results suggest that the optimum value for elastic normal stiffness is $4000 \mathrm{kN} / \mathrm{m}$. This contradicts the result of $1000 \mathrm{kN} / \mathrm{m}$ as found by Yetimoglu et al. ${ }^{[4]}$ who worked on rectangular footings. The disagreement may be attributed to the difference in geogrid material properties and the geometric dimensions of the geogrid used

7. The dilatancy angle (?) for reinforced soil foundations causes an increase in $B C R$ for any all settlement levels and for $\psi \leq \phi / 4$, there is no significant change in $B C R$.

8. For settlement ratios $(s / B)$ of $2.5 \%$ to $5 \%, 5 \%$ to $7.5 \%$ and $7.5 \%$ to $B C R_{u}$, there is $107 \%, 44 \%$, and $21 \%$ (respectively) increase in tensile force. This means that; increasing the settlement level ratio, the increamental increase in tensile force is less. However, with increasing unit weight, there is no significant change in reinforcement tensile force

9. The average bearing capacity for settlement levels of $2.5 \%, 5 \%$, and $7.5 \%$ is $70 \%, 80 \%$, and $86 \%$ of ultimate bearing capacity respectively

10. With application of a constant load; the reinforcement tensile force decreases with increasing the value of $E$. This is due to the increase of sand stiffness; causing the tensile force to decrease. Also, an increase of soil stiffness; causes a decrease in deformation (settlement) and; a corresponding decrease in the reinforcement strain.

11. When the granular soil Poissons ratio varies from 0.2 to 0.4 the rate of $B C R$ increase, for increasing settlement levels, is very high with a (parallel) average slope of 65 degrees.

12. The $B C R$ decreases with increase in foundation diameter. The reason seems to be that; with increase in dimension of foundation, the normal force which creates friction strength between soil and reinforcement is decreased. Hence, the reinforcement tensile force decreases and the reinforcement is not activated bringing it in line with the unreinforced soil

13. The value of $B C R$, at a given tensile force, is at its maximum for a foundation diameter of $1.5 \mathrm{~m}$. (i.e. circular foundations with a diameter greater than $1.5 \mathrm{~m}$ do not effect the $B C R$ ). This appears to be similar to the laboratory works of Das and Omar ${ }^{[14]}$ who worked on strip foundation.
Multiple layers of geogrid reinforcement:

1. The optimum value for $h / B$ is approximately 0.3 . This value is slightly higher than the 0.25 suggested by Singh $^{[11]}$ and 0.20 suggested by Yetimouglu et al. ${ }^{[4]}$. Furthermore, for the case of $h / B$ less than 0.5 , the wedge failure shear penetrates into reinforcement zone; activating the reinforcement; and causing an increase in the bearing capacity

2. The optimum number of layers of reinforcement to achieve the maximum $B C R$ is 3 . This confirm the works of Akinmusuru and Akinbolade ${ }^{[12]}$, and Guido et al. ${ }^{[8]}$ who reported that; the rate of increase in $B C R$ would decrease beyond 3 layers of reinforcement. However, the results disagree with the findings reported by Yetimoglu et al. ${ }^{[4]}$ who reported that; the optimum number of reinforcement layers was 4 , corresponding to a reinforcement depth of $1.5 \mathrm{~B}$, and Omar et al. ${ }^{[14]}$, Booshehrian and Hatef ${ }^{[15]}$ who found that; the optimum number of layers of reinforcement to achieve the maximum $B C R$ was 4 . These differences; may be due to the differences in the material properties and the geometric dimensions of the geogrid used in the different studies

3. For any number of reinforcement layers and settlement ratio levels up to $2.5 \%$, the $B C R_{S} \approx 0.80 B C R_{u}$. It appears that; with an increase in the reinforcement depth ratio, the normal force in the soil decreases; resulting in a corresponding decrease in the friction between the soil and reinforcement. Hence, placing the reinforcement at a greater embedment depth; does not increase the bearing capacity. The friction forces for circular foundations at a depth of $2 B$ approches zero.

Overall, the improvement in the foundation properties due to the reinforcement is attributed to the fact that the shearing strength of the soil column below the foundation is increased and the geogrid-sand system acts as a composit material and prevents the distribution of soil wedge failure below the foundations base.

Design curves presented are developed to assist with the estimation (design) of field bearing capacity of shallow foundations supported by geogrid reinforced soil. Keeping in mind the settlement limitations in real space, the curves have been developed for normal settlement levels up to a settlement ratio of $2.5 \%$. 
Am. J. Applied Sci., 5 (4): 355-368, 2008

\section{ACKNOWLEDGMENT}

We would like to express our sincere appreciation to Mr. Ted McDonnell for his valuable role in this research.

\section{REFERENCES}

1. Shin, E.C., Das, B.M., Lee, E.C. and Atalar, C. 2002. Bearing capacity of strip footing on geogrid reinforced sand. Geotechnical and Geological Engineering Journal. Vol. 20, pp.169-180

2. Adams, M.T. and Collin, J.C. 1997. Large model spread footing load tests on geosyntetic reinforced soil foundation. Journal of Geotechnical and Geoenvironmental Engineering. ASCE, Vol. 123, No. 1, pp. 66-72

3. Das, B.M. 1995. Principles of foundation engineering. $3^{\text {rd }}$ Editions, PWS-Kent, Boston, M.A., USA

4. Yetimoglu, T., Wu, J.T.H., and Saglamar, A. 1994. Bearing capacity of rectangular footings on geogrid-reinforced sand. Journal of Geotechnical Engineering. ASCE, Vol. 120, No. 12, pp.20832099

5. Khing, K.H., Das, B.M., Puri, V.K., Cook, E.E. and Yen, S.C. 1993. The bearing capacity of a strip foundation on geogrid-reinforced sand. Geotextiles and Geomembrane. Vol. 12, No. 4. pp.351-361

6. Omar, M.T., Das, B.M., Yen, S.C., Puri, V.K. and Cook, E.E. 1993. Ultimate bearing capacity of rectangular foundations on geogrid-reinforced sand. Geotechnical Testing Journal. ASTM, Vol. 15, No. 2, pp.246-252

7. Guido, V.A., Dong, K.G., and Sweeny, A. 1986. Comparison of geogrid and geotextile reinforced earth slabs. Canadian Geotechnical Journal. Vol. 23, No.1, pp. 435-440

8. Guido, V.A., Biesiadecki, G.L., and Sullivan, M.J. 1985. Bearing capacity of a geotextile reinforced foundation. Proc. $11^{\text {th }}$ Int. Conf. Soil Mechanic and Foundation Engineering, San Francisco, California. Vo1. 3, pp. 1777-1780
9. Drucker D.C. and Prager, W. 1952. Soil mechanics and plastic analysis of limit design. Quart. Applied Mathematics. Vol. 10, No. 2

10. Pfeifle, T.W., and Das, B.M. 1979. Model test for bearing capacity in sand. Journal of Geotechnical Engineering. ASCE, Vol. 105, pp.1112-1116

11. Singh, H.R. 1988. Bearing capacity of reinforced soil beds. Ph.D. Thesis . Indian Institute of Science, Bangalore, India

12. Akinmusuru, J.O., and Akinbolade, J.A. 1981. Stability of loaded footings on reinforced soil. Journal of Geotechnical Engineering. ASCE, Vol. 107, No. 6, pp.819-827

13. Guido, V.A., Knueppel, J.D., and Sweeny, A. 1987. Plate loading test on geogrid reinforced earth slabs. Proceedings Geosynthetics' 87 Conference, New Orleans. pp216-225

14. Omar, M.T., Das, B.M., Puri, V.K, Cook, E.E., and Yen, S.C. 1994. Bearing capacity of foundation on geogrid-reinforced sand. Proc. $7^{\text {th }}$ Int. Conf. on Mechanic and Foundation Engineering, Balkemia Rotterdam, The Netherland. Vol. 3, pp.1279-1282

15. Booshehrian, J.H. and Hatef, N. 2003. Experimental and numerical investigation of the bearing capacity of model circular and ring footing on reinforced sand. Journal of Geotextiles and Geomembranes. Vol. 21, pp.241-256

16. Das, B.M., Omar, M.T. 1994. The effects of foundation width on model tests for bearing capacity of sand with geogrid reinforcement. Geotechnical and Geological Engineering Journal. Vol.12, No. 2, pp.133-141

17. Terzaghi, K. 1943. Theoretical soil mechanics. Wiley, Inc, New York. 